\title{
Empirical Analysis on Function Mechanism of Factors Affecting the Efficiency of China's Agricultural Products Logistics
}

\author{
Sheng Zhong \\ College of Business Administration, Jiangxi University of Finance and Economics, Nanchang 330013, China
}

Corresponding Author Email: zsshark07@sina.com

https://doi.org/10.18280/jesa.520203

Received: 4 January 2019

Accepted: 16 March 2019

\section{Keywords:}

agricultural products logistics, technical efficiency, influencing factors, function mechanism

\begin{abstract}
Despite being a research hotspot, most studies on the efficiency of agricultural products logistics in China stop at analyzing the influencing factors, measuring efficiency level, and discussing the impacts of exogenous environmental factors. However, there is no in-depth report on the function mechanism of the influencing factors. To make up for this gap, this paper evaluates the technical efficiency of China's agricultural products logistics using slacksbased measure data envelope analysis (DEA-SBM), explores how exogenous environmental factors and upstream/downstream industrial factors of agricultural products supply chain influence the technical efficiency of China's agricultural products logistics, and further discusses the function mechanism of each type of influencing factors.
\end{abstract}

\section{INTRODUCTION}

China is a traditional agricultural country with a large population. The large scale of agricultural production, coupled with the huge demand for agricultural products, has spawned a gigantic logistics market of agricultural products. In recent years, the total logistics volume of agricultural products in China has surpassed RMB 4 trillion yuan. Against this background, maintaining the efficient operation of agricultural products logistics is a necessary condition for further promoting the efficiency of agricultural economy and satisfying the social demand for agricultural products.

The existing studies on the efficiency of agricultural products logistics mainly focus on the influencing factors and the measurement of the efficiency level. The influencing factors have been explored from the angles of organization, technology and policy. From the perspective of organization, it is agreed that the organization of agricultural product logistics directly bears on the logistics efficiency. For instance, Sui and Zhuang regarded third-party logistics as the key to the efficiency of agricultural products logistics [1]. Accorsi treated economic globalization as an important impactor of the efficiency of agricultural product logistics, and explained that the globalization trend has complicated the supply network of agricultural products, inducing great changes to the operation of logistics links between the nodes [2]. Lei et al. held that the efficiency of agricultural products logistics can be improved by optimizing the supply and demand system of agricultural products logistics, developing e-commerce models for agricultural products, and third-party logistics enterprises [3]. From the perspective of technology, the efficiency of agricultural products logistics can be promoted by logistics infrastructure, employee quality, cold chain logistics technology, information level and urbanization level. For example, Cameron pointed out the important role of information technology in agricultural products logistics, and listed it as a key influencing factor of logistics efficiency [4].
From the perspective of policy, the previous research has shown that the government support helps to enhance the efficiency of agricultural products logistics. For instance, Yang discovered the major impacts of government policies like legal system construction, market access standard and tax reduction/exemption on the efficiency of agricultural products logistics [5]. So far, the efficiency level of agricultural products logistics has been measured by factor analysis, analytic hierarchy process (AHP), stochastic frontier analysis (SFA) and data envelope analysis (DEA), yielding fruitful results. For example, Wang and Wen evaluated the efficiency of China's agricultural products logistics in 2003 2011 by the SFA, revealing that the efficiency decreases progressively from the eastern region, central region to western region [6].

Nevertheless, there is no report on the function mechanism of the influencing factors, calling for in-depth research on the reasons for the correlation between these factors and the efficiency of agricultural products logistics.

\section{TECHNICAL EFFICIENCY MEASUREMENT OF CHINA'S AGRICULTURAL PRODUCTS LOGISTICS}

According to Farrell's efficiency theory [7], the efficiency can be decomposed into technical efficiency(TE) and allocation efficiency(AE). Meanwhile, technical Efficiency can be further decomposed into the product of pure technical efficiency (PTE) and scale efficiency (SE).However, it is difficult to obtain the price of the input elements of agricultural product logistics in different regions and periods, making it impossible to compute the allocation efficiency. Hence, this paper decides to explore the technical efficiency of agricultural products logistics in China, which is in line with the traditional practice of treating technical efficiency as the research target. 


\subsection{Model setting}

The DEA is the most common nonparametric method for measuring technical efficiency. However, the traditional DEA models of Chames-Cooper-Rhodes (CCR) and BankerChames-Cooper (BCC) have the defect of weak efficiency. To solve the defect, this paper selects the non-radial, non-angled slacks-based measure (SBM) DEA model (DEA-SBM). The SBM model, proposed by Tone [8], introduces the slack variable directly into the objective function. In this way, the effects of slack input and output are considered in efficiency calculation, thereby overcoming the weak efficiency problem.

Let $\mathrm{n}$ be the number of decision-making units (DMUs), each of which has $\mathrm{m}$ inputs and $\mathrm{k}$ outputs. Then, the SBM model with constant returns to scale (CRS) can be expressed as:

$$
\begin{array}{r}
\min \rho=\frac{1-\frac{1}{m} \sum_{i=1}^{m} s_{i}^{-} / x_{i 0}}{1-\frac{1}{k} \sum_{r=1}^{k} s_{r}^{+} / \mathrm{y}_{r 0}} \\
\text { s.t. }\left\{\begin{array}{l}
x_{0}=X \lambda+s^{-} \\
y_{0}=Y \lambda-s^{+} \\
\lambda \geq 0, s^{+} \geq 0, s^{-} \geq 0
\end{array}\right.
\end{array}
$$

where, $\mathrm{s}^{-}$and $\mathrm{s}^{+}$are excess input and insufficient output, respectively; $\rho(0<\rho \leq 1)$ is the efficiency evaluated by the model. The value of $\rho$ is 1 only if $\mathrm{s}^{-}=\mathrm{s}^{+}=0$, i.e. the DMU is valid for the SBM. Therefore, there is no "weak efficiency" problem with the SBM model. The SBM model under the variable returns to scale (VRS) can be obtained by adding the constraint $\sum \lambda_{\mathrm{j}}=1(\mathrm{j}=1,2, \ldots, \mathrm{n})$ to equation (1).

\subsection{Index setting, sample selection and data collection}

(1) Input and output indices. The Cobb-Douglas production function is defined as:

$$
Q(\mathrm{~K}, \mathrm{~L})=\mathrm{AK}^{\alpha} L^{\beta}, 0<\alpha, \beta<1
$$

where, $Q$ is the output; $A$ is the technical level; $K$ is the capital; $L$ is the labor force; $\alpha$ is the elastic coefficient of capital output; $\beta$ is the elastic efficient of labor output. It can be seen that the output is mainly affected by such input factors as capital and labor force under the given technical level.

On capital input, the capital stock of agricultural products logistics was selected as the indicator of the continued effect of upfront capital, and verified by the popular "perpetual inventory method":

$$
K_{i t}=K_{i t-1}(1-\delta)+\mathrm{I}_{i t}
$$

where, $K_{i t}$ and $K_{i t-1}$ are the capital stock of regional agricultural products logistics in provincial-level administrative region $\mathrm{i}$ in the period $\mathrm{t}$ and the period $t-1$, respectively; $\delta$ is the depreciation rate; $I_{i t}$ is the capital input of regional agricultural products logistics of provincial-level administrative region $i$ in the period $t$.

In this paper, the capital stock of the base year (1981) is estimated by the method proposed by Hall and Jones [9]. Specifically, the social fixed investment on agricultural products logistics in 1981 was divided by the sum between the geometric mean growth rate of the social fixed investment on agricultural products logistics and the depreciation rate in 1981 2014, yielding the capital stock of agricultural products logistics in each provincial-level administrative region in 1981. Inspired by Zhang et al. [10], the depreciation rate $\delta$ in equation (3) was calculated by the balance depreciation method representing the decreasing geometric efficiency, under the assumption that the relative efficiency of capital goods decrements geometrically:

$$
d_{\tau}=(1-\delta)^{\tau}, \tau=0,1, \cdots
$$

where, $\mathrm{d}_{\tau}$ is the relative efficiency of capital goods; $\delta$ is the depreciation rate; $\tau$ is the service life. When the relative efficiency of capital goods decrements geometrically, the distribution of the depreciation rate in each year remains constant. The results of Huang et al. show that: the relative efficiency of capital goods $\mathrm{d}_{\tau}$ can be replaced with the legal residual rate [11]. In light of this, the legal residual rate was set to $4 \%$, a medium value in the value range of $3 \% \sim 5 \%$.

The $I_{i t}$ was measured by the social fixed investment of agricultural products logistics, and the investment in each year was deflected by the constant price in 1981. In terms of labor input, the number of employees of agricultural products logistics was represented by that of transport, warehousing and postal service, which are the mainstay of the logistics industry. In addition, the regional agricultural products turnover was set as the output index. This index, measured in units of 100 million tons, is not affected by price fluctuations. It is an ideal output variable, capable of depicting the freight volume and freight distance at the same time.

(2) Sample selection and data collection. The research samples include 28 provincial-level administrative regions, excluding areas with severe data loss. To facilitate comparison, the 28 regions were divided into eastern China, central China and western China. The data used in the research mainly come from official statistical reports like the China Statistical Yearbooks 2000 2015 and China Fixed Assets Investment Statistics Yearbook, aiming to ensure the data authenticity and accuracy.

\subsection{Measured results of technical efficiency}

With the aid of MaxDEA Pro 6.8, this paper measures TE of agricultural products logistics in 2000 2015 in Chinese mainland, and decomposes it into PTE and SE (Table 1) according to Farrell's theory on efficiency (1957).

The data in Table 1 shows that the overall technical efficiency is low for China's agricultural products logistics. This is mainly attributable to the low PTE and high SE. Through regional comparison, eastern China enjoys the highest PTE while central China has a slight lead over western China in the PTE; in terms of the SE, the three regions are ranked in descending order as: central China, western China and eastern China. 
Table 1. Technical efficiency and its decomposition results of agricultural products logistics in Chinese mainland in $2000 \sim 2015$

\begin{tabular}{|c|c|c|c|c|c|c|c|c|c|c|c|c|c|c|c|c|c|}
\hline & & 00 & 01 & 02 & 03 & 04 & 05 & 06 & 07 & 08 & 09 & 11 & 10 & 12 & 13 & 14 & 15 \\
\hline \multirow{3}{*}{$\begin{array}{c}\text { Eastern } \\
\text { mean }\end{array}$} & TE & 0.342 & 0.350 & 0.309 & 0.728 & 0.258 & 0.254 & 0.276 & 0.269 & 0.453 & 0.419 & 0.436 & 0.430 & 0.382 & 0.288 & 0.298 & 0.387 \\
\hline & PTE & 0.579 & 0.566 & 0.561 & 0.810 & 0.570 & 0.576 & 0.592 & 0.605 & 0.600 & 0.642 & 0.609 & 0.694 & 0.706 & 0.579 & 0.582 & 0.628 \\
\hline & $\mathrm{SE}$ & 0.719 & 0.755 & 0.727 & 0.906 & 0.687 & 0.634 & 0.642 & 0.610 & 0.827 & 0.758 & 0.772 & 0.729 & 0.668 & 0.635 & 0.642 & 0.700 \\
\hline \multirow{3}{*}{$\begin{array}{c}\text { Central } \\
\text { mean }\end{array}$} & TE & 0.183 & 0.170 & 0.151 & 0.388 & 0.098 & 0.093 & 0.104 & 0.102 & 0.359 & 0.344 & 0.355 & 0.355 & 0.344 & 0.304 & 0.300 & 0.348 \\
\hline & PTE & 0.226 & 0.191 & 0.177 & 0.411 & 0.113 & 0.125 & 0.130 & 0.132 & 0.381 & 0.368 & 0.385 & 0.395 & 0.407 & 0.357 & 0.347 & 0.372 \\
\hline & $\mathrm{SE}$ & 0.849 & 0.903 & 0.898 & 0.962 & 0.913 & 0.813 & 0.848 & 0.830 & 0.927 & 0.917 & 0.912 & 0.898 & 0.849 & 0.828 & 0.830 & 0.910 \\
\hline \multirow{3}{*}{$\begin{array}{l}\text { Western } \\
\text { mean }\end{array}$} & TE & 0.107 & 0.099 & 0.087 & 0.252 & 0.055 & 0.051 & 0.062 & 0.061 & 0.193 & 0.172 & 0.182 & 0.182 & 0.177 & 0.136 & 0.131 & 0.166 \\
\hline & PTE & 0.202 & 0.194 & 0.215 & 0.362 & 0.152 & 0.148 & 0.158 & 0.157 & 0.372 & 0.355 & 0.362 & 0.362 & 0.361 & 0.330 & 0.325 & 0.363 \\
\hline & $\mathrm{SE}$ & 0.903 & 0.906 & 0.789 & 0.806 & 0.903 & 0.903 & 0.903 & 0.904 & 0.815 & 0.816 & 0.819 & 0.820 & 0.797 & 0.774 & 0.774 & 0.760 \\
\hline \multirow{3}{*}{$\begin{array}{l}\text { National } \\
\text { mean }\end{array}$} & TE & 0.213 & 0.209 & 0.185 & 0.461 & 0.140 & 0.136 & 0.150 & 0.147 & 0.333 & 0.309 & 0.322 & 0.320 & 0.298 & 0.238 & 0.239 & 0.297 \\
\hline & PTE & 0.343 & 0.326 & 0.328 & 0.536 & 0.290 & 0.294 & 0.305 & 0.310 & 0.456 & 0.461 & 0.457 & 0.490 & 0.497 & 0.426 & 0.423 & 0.460 \\
\hline & $\mathrm{SE}$ & 0.822 & 0.851 & 0.798 & 0.886 & 0.829 & 0.782 & 0.794 & 0.778 & 0.851 & 0.824 & 0.829 & 0.810 & 0.766 & 0.740 & 0.743 & 0.782 \\
\hline
\end{tabular}

\section{FUNCTION ANALYSIS ON UPSTREAM AND DOWNSTREAM INFLUENCING FACTORS OF AGRICULTURAL PRODUCTS SUPPLY CHAIN}

In general, the previous research only discusses the impact of exogenous environmental factors. This paper innovatively includes the upstream and downstream industrial factors of agricultural products supply line into the research scope. The upstream industry is defined as agriculture, while the downstream industry is defined as the agricultural products processing and retailing. The three industries are all creators of the demand for agricultural products logistics. The scale of each industry has a major impact on the resource convergence and operation of agricultural product logistics.

\subsection{Index settings and data sources}

The total output of agriculture, forestry, animal husbandry and fishery was selected to depict the scale of agriculture; the net value of fixed asset was selected to describe the scale of agricultural products processing; due to the lack of data on agricultural products retailing, the expenditure of urban residents on agricultural products was chosen to replace the scale of agricultural products retailing. The three indices were all deflected according to the constant price of the base year (1981).

\subsection{Influence measurement}

(1) Stationarity test. For each provincial administrative region, the technical efficiency (XL) of agricultural products logistics was taken as the explained variable of regression analysis, and the total output of agriculture, forestry, animal husbandry and fishery (NY), net fixed value of agricultural products processing (JGY) and expenditure on agricultural products (XS) were taken as the explanatory variables. To eliminate the heteroscedasticity in the collected data, this paper carries out natural logarithm processing of the above indices, which does not affect the nature and correlation between data.

Table 2. Unit root test of panel data

\begin{tabular}{|c|c|c|c|c|c|c|}
\hline Variable & Test Value & LLC & Im- Pesaran and Shin W-stat & ADF - Fisher Chi-squareI & PP - Fisher Chi-square & Conclusion \\
\hline \multirow{2}{*}{ DLNXL } & $\mathrm{I}(1)$ & -10.394 & -5.88955 & 160.701 & 183.069 & \multirow{2}{*}{ stable } \\
\hline & P Value & 0 & 0 & 0 & 0 & \\
\hline \multirow{2}{*}{ DLNNY } & $\mathrm{I}(1)$ & -8.323 & -7.36952 & 152.5 & 171.594 & \multirow{2}{*}{ stable } \\
\hline & P Value & 0 & 0 & 0 & 0 & \\
\hline \multirow{2}{*}{ DLNXS } & $\mathrm{I}(1)$ & -13.590 & -7.36952 & 152.5 & 171.594 & \multirow{2}{*}{ stable } \\
\hline & P Value & 0 & 0 & 0 & 0 & \\
\hline \multirow{2}{*}{ DLNJGY } & $\mathrm{I}(1)$ & 0 & 180.526 & 210.963 & 0 & \multirow{2}{*}{ stable } \\
\hline & P Value & 0 & 0 & 0 & 0 & \\
\hline
\end{tabular}

Table 3. Co-integration test results on the stationarity of first-order differential of the residual

\begin{tabular}{c|c|c|c|c}
\hline & Statistic & Prob. ${ }^{* *}$ & Cross-sections & Obs \\
\hline Null: Unit root (assumed common unit root process) & & \\
\hline Levin, Lin \& Chu t* & -18.342 & 0 & 28 & 338 \\
\hline Null: Unit root (assumes individual unit root process) & \\
\hline Im, Pesaran and Shin W-stat & -15.722 & 0 & 28 & 338 \\
\hline ADF - Fisher Chi-square & 306.834 & 0 & 28 & 338 \\
\hline PP - Fisher Chi-square & 658.756 & 0 & 28 & 364 \\
\hline
\end{tabular}

The EViews 9.0 was adopted to test the stationarity of the collected panel data to prevent the pseudo-regression caused by data instability. Table 2 shows the test results after the firstorder difference of each variable. It can be seen that DLN-XL, DLN-NY, DLN-JGY and DLN-XS rejects the original hypothesis "the existing of unit root", that is, the crosssectional sequence is stable after the first-order differentiation.

(2) Co-integration test. The Engle-Granger (E-G) two-step method was adopted for the co-integration test. The results in Table 3 show that the absolute values of the statistics are great 
under any test method, and the corresponding probability values $\mathrm{P}$ are almost all zero. Therefore, the original hypothesis that "the residual sequence of all cross-section regression equations has a unit root" should be rejected. Thus, there exists a co-integration relationship between panel data sequences DLN-XL, DLN-NY, DLN-JGY and DLN-XS, and the regression residuals of the equations are stable and can be subjected to regression analysis.

(3) Regression analysis. The panel data can be expressed by the model below:

$$
\begin{aligned}
& y_{i}=\alpha_{i}+x_{i} \beta_{i}+\mu_{i} \\
& i=1,2, \cdots, N
\end{aligned}
$$

where, $y_{i}$ is the vector of the $\mathrm{T} \times 1$-dimensional explained variable; $x_{i}$ is the $\mathrm{T} \times \mathrm{k}$-dimensional matrix of explanatory variables; the components of $y_{i}$ and $x_{i}$ form the time sequence of individual economic index; $\alpha_{i}$ and $\beta_{i}$ are the intercept term and $\mathrm{k} \times 1$-dimensional coefficient vector; $\mu_{I}$ is a $\mathrm{T} \times 1$ dimensional vector of the perturbation term, which satisfies the hypothesis of the mean value is zero and the variance is $\sigma_{\mu}^{2}$.

By the intercept term and the coefficient value, model (5) can be divided into three forms: the chche $\alpha_{i}=\alpha_{j}, \beta_{i}=\beta_{j}$, the variable intercept model $\alpha_{i} \neq \alpha_{j}, \beta_{i}=\beta_{j}$, and the variable parameter model $\alpha_{i} \neq \alpha_{j}, \beta_{i} \neq \beta_{j}$. The model form should be selected through testing the following two hypotheses:

$$
\begin{aligned}
& H_{1}: \beta_{1}=\beta_{2}=\ldots=\beta_{N} \\
& H_{2}: \alpha_{1}=\alpha_{2}=\ldots=\beta_{N} ; \beta_{1}=\beta_{2}=\ldots=\beta_{N}
\end{aligned}
$$

If hypothesis $\mathrm{H}_{2}$ is acceptable, the invariant coefficient form should be adopted for the model; otherwise, it is necessary to test hypothesis $\mathrm{H}_{1}$. If hypothesis $\mathrm{H}_{1}$ is acceptable, the variable intercept form should be adopted for the model; otherwise, the variable parameter form should be adopted for the model. The above hypotheses should be judged by the value of the Fstatistics $F_{1}$ and $F_{2}$, which can be calculated by:

$$
\begin{gathered}
F_{1}=\frac{\left(S_{2}-S_{1}\right) /[(N-1) k]}{S_{1} /(N T-N(k+1))} \sim F[(N-1) k, N(T-k-1)] \\
F_{2}=\frac{\left(S_{3}-S_{1}\right) /[(N-1)(k+1)]}{S_{1} /(N T-N(k+1))} \sim F[(N-1)(k+1), N(T-k-1)]
\end{gathered}
$$

After regression, the residual sum of squares of each of the above three models was $\mathrm{S}_{1}=30.41984, \mathrm{~S}_{2}=37.54385$ and $\mathrm{S}_{3}=38.52262$. The values of $\mathrm{F}_{1}$ and $\mathrm{F}_{2}$ were computed by substituting $\mathrm{S}_{1}, \mathrm{~S}_{2}$ and $\mathrm{S}_{3}$ into equations (7) and (8), respectively, with $\mathrm{N}=28, \mathrm{~T}=16$ and $\mathrm{k}=3$. Finally, it is obtained that $F_{2}=0.654 \sim(108,336)$. Then, the critical value of the $F$ distribution can be derived by function @qfdist $\left(\mathrm{d}, \mathrm{k}_{1}, \mathrm{k}_{2}\right)$, where $\mathrm{d}$ is the critical point, and $\mathrm{k}_{1}$ and $\mathrm{k}_{2}$ are the degrees of freedom. The critical value of $\mathrm{F}_{2}$ was calculated as 1.282 at the significance level of $5 \%$ (when $\mathrm{d}=0.95$ ). Since $\mathrm{F}_{2}<1.282$, hypothesis $\mathrm{H}_{2}$ is acceptable. Thus, the invariant coefficient form should be adopted for the model (Table 4).

Table 4. Regression results of invariant coefficient model

\begin{tabular}{c|c|c|c|c}
\hline Variable & coefficient & Std.Error & t.Statistic & Prob. \\
\hline C & 0.05407 & 0.031635 & 1.70924 & 0.0882 \\
\hline DLNNY? & -1.16955 & 0.438918 & -2.66462 & 0.008 \\
\hline DLNXS? & 0.28713 & 0.377008 & 0.76160 & 0.4467 \\
\hline DLNJGY? & 0.33911 & 0.084389 & 4.01841 & 0.0001 \\
\hline
\end{tabular}

\section{FUNCTION ANALYSIS OF EXOGENOUS ENVIRONMENTAL FACTORS}

The agricultural products logistics is a production system. The system operations are inevitably affected and constrained by the external macro-environment. Thus, the technical efficiency is subjected to the impacts from exogenous environmental factors.

\subsection{Index setting and data sources}

Referring to Xu and Li [12], Yuan and Lei [13] and Ni et al. [14], this paper selects five exogenous environmental factors, including regional economic development, the openness, the industrial structure, the information level and the institutional environment. The five factors respectively correspond to the per capital GDP, the foreign trade dependence (the ratio of total import/export of agricultural products to the GDP), the ratio of the tertiary industry added value to the regional GDP, the information development index (IDI) issued by National Bureau of Statistics, and the state-owned ratio (the ratio of the investment by state-owner investors to the social fixed investment).

\subsection{Analysis model}

The technical efficiency fell between 0 and 1, which reflects the features of the truncated data. Therefore, the standard Tobit truncation model was selected for analysis [15]:

$$
\begin{aligned}
& y^{*}=x^{*} \beta+\varepsilon \\
& y= \begin{cases}0, & y^{*} \leq 0 \\
y^{*} & y^{*} \leq 0\end{cases}
\end{aligned}
$$

where, $\varepsilon \sim\left(0, \sigma^{2}\right)$. In the above model, $y$ is set as the mean the production efficiency of the agricultural logistics in the three regions. The independent variables of the model are the five indices mentioned in Section 3.1.

\subsection{Analysis of the results of Tobit model}

Table 5 lists the results of Tobit model in different regions: $\mathrm{X}_{1}$ - per capita GDP; $\mathrm{X}_{2}$ - foreign trade dependence; $\mathrm{X}_{3}$ - the ratio of the tertiary industry added value to the regional GDP; $\mathrm{X}_{4}$ - the IDI; $\mathrm{X}_{5}$ is the state-owned ratio. 
Table 5. Results of Tobit model

\begin{tabular}{|c|c|c|c|c|c|}
\hline & variable & Coefficient & Std. Error & z-Statistic & Prob. \\
\hline \multirow{6}{*}{$\begin{array}{c}\text { Eastern } \\
\text { mean }\end{array}$} & $\mathrm{C}$ & -1.463671 & 0.350597 & -4.174802 & $0.000000^{*}$ \\
\hline & $\mathrm{X}_{1}$ & -0.00000286 & 0.00000172 & -1.664772 & $0.096000 * * *$ \\
\hline & $\mathrm{X}_{2}$ & -1.033496 & 2.37263 & -0.435591 & 0.663100 \\
\hline & $\mathrm{X}_{3}$ & 2.380034 & 0.462637 & 5.144497 & $0.000000^{*}$ \\
\hline & $\mathrm{X}_{4}$ & 0.006297 & 0.001981 & 3.178825 & $0.001500^{*}$ \\
\hline & $\mathrm{X}_{5}$ & 1.01991 & 0.266109 & 3.832678 & $0.000100^{*}$ \\
\hline \multirow{6}{*}{$\begin{array}{c}\text { Central } \\
\text { mean }\end{array}$} & $\mathrm{C}$ & -0.61311 & 0.210788 & -2.908659 & $0.003600^{*}$ \\
\hline & $\overline{X_{1}}$ & 0.0000759 & 0.00000675 & 11.2455 & $0.000000^{*}$ \\
\hline & $\mathrm{X}_{2}$ & 20.92372 & 6.795492 & 3.079059 & $0.002100^{*}$ \\
\hline & $\mathrm{X}_{3}$ & -1.779012 & 0.487145 & -3.651916 & $0.000300^{*}$ \\
\hline & $\mathrm{X}_{4}$ & 0.006836 & 0.002167 & 3.154668 & $0.001600^{*}$ \\
\hline & $\mathrm{X}_{5}$ & 1.500783 & 0.197684 & 7.591834 & $0.000000^{*}$ \\
\hline \multirow{6}{*}{$\begin{array}{c}\text { Western } \\
\text { mean }\end{array}$} & $\mathrm{C}$ & -0.115309 & 0.362436 & -0.318151 & 0.750400 \\
\hline & $\mathrm{X}_{1}$ & 0.0000248 & 0.0000113 & 2.200894 & $0.027700 * *$ \\
\hline & $\mathrm{X}_{2}$ & -3.872025 & 13.36884 & -0.28963 & 0.772100 \\
\hline & $\mathrm{X}_{3}$ & 0.277947 & 0.871402 & 0.318966 & 0.749800 \\
\hline & $\mathrm{X}_{4}$ & 0.001496 & 0.003088 & 0.48458 & 0.628000 \\
\hline & $\mathrm{X}_{5}$ & 0.017453 & 0.093322 & 0.187014 & 0.851600 \\
\hline
\end{tabular}

Note: “*”-1\% significance level; “**”-5\% significance level; “***”-10\% significance level.

\section{ANALYSIS OF FUNCTION MECHANISM}

As mentioned above, the technology efficiency of agricultural products logistics is obviously under the direct impacts from the input and output factors, the upstream and downstream factors of agricultural products supply chain, as well as the exogenous environmental factors. However, the existing studies has not discussed about the reason behind the impacts.

\subsection{Analysis of the function mechanism of input and output factors}

(1) PTE. The PTE reflects how effective a DMU utilizes the existing resources. From the angle of capital investment, the PTE is usually affected by the decision-maker's performance in capital investment professionality, capital utilization ability, government regulation and the "overflow effect". Specifically, the capital investment professionality refers to whether the software/hardware facilities and equipment built with capital investment satisfy the actual needs of agricultural products logistics. The capital utilization ability mainly covers the design, implementation and control abilities of the agricultural products logistics plans based on the existing facilities and equipment. The government control reveals the government departments' ability to regulate the agricultural products logistics market. The "overflow effect" means the dissemination of knowledge, experience, methods and techniques in the utilization of the capital for agricultural product logistics among different entities.

None of the above aspect is satisfactory concerning the status quo of China's agricultural products logistics, leading to poor technical efficiency and wide regional differences. Taking the capital investment professionality as an example, the governments at all levels and enterprises have spent far too few money on the purchase of special cold chain equipment for agricultural products logistics, the construction of professional parks or distribution centers for agricultural products logistics, or the research and design of agricultural products logistics technologies.

The PTE is also affected by the quality of the labor input. Currently, most of the employees in China's agricultural products logistics do not have a high degree or receive professional education. The relatively poor labor quality directly affects the actual operational capacity of agricultural product logistics.

Eastern China enjoys advantages in all the above aspects. For example, most of the few professional parks for agricultural products logistics are concentrated in eastern China; the employees of agricultural products logistics in eastern China are more professional than those in central and western China, thanks to the advanced education industry in this region. Overall, eastern China has better PTE than the other two regions.

(2) SE. The SE is mainly influenced by the amount of capital input and labor input. In eastern China, lots of capital flow into the vast market of agricultural products logistics, surpassing the actual demand for agricultural products logistics in that region; meanwhile, too many labor resources have accumulated in eastern China, due to the favorable working environment, salary and living conditions, making this region the lowest in scale efficiency. In western China, the agricultural products logistics started late, faces short supply and lacks sufficient scale, although agriculture has long been the pillar industry in the region. As a result, the scale efficiency of western China is lower than that of central China.

\subsection{Analysis of the function mechanism of upstream and downstream factors in the agricultural products supply chain}

At present, the main operation mode of China's agricultural product logistics is centered on the multi-level wholesale market. The agricultural products are transferred level by level from the upstream agriculture to the downstream processing industry and retail industry for agricultural products. This operation mode involves numerous small enterprises with poor ability in agricultural products operation. These enterprises are highly scattered, lacking unified planning. The defects of this operation mode severely affect the PTE, and the negative impact increases with the scale of agriculture. Therefore, the expansion of agriculture scale has an obvious suppression effect on the technical efficiency of agricultural products logistics. 
Recent years has seen the emergence and growing popularity of direct purchase in the retail industry and processing industry for agricultural products. The new mode of "enterprise + farmer + base" can circumvent the wholesale markets at all levels and avoid the defects of the traditional mode centering on the multi-level wholesale market. In this mode, the expansion of agricultural products retailing has an unobvious promotion effect on the technical efficiency, while that of agricultural products processing has an obvious promotion effect on that issue.

\subsection{Analysis of the function mechanism of exogenous environmental factors}

(1) Regional economic development. The coefficient of the $\mathrm{X}_{1}$ variable in each of the three regions was very small, indicating that the regional economic development has virtually no effect on the technical efficiency. The main reason is that the regional economy mainly promotes the industrial goods logistics, rather than the agricultural products logistics, which has a relatively small profit margin.

(2) Openness. Central China mainly imports and exports land-intensive agricultural products like grain and cotton, which has relatively low logistics difficulty. The domestic enterprises differ slightly from foreign enterprises in the logistics of these products. With a relatively high operation ability of logistics, the foreign enterprises will exhibit an obvious promotion effect of "technical spillover" after entering the domestic market of agricultural products logistics.

Eastern China mainly imports and exports land-intensive agricultural products requiring cold chain logistics, such as vegetables, fruits, fresh meat and frozen meat, adding to the difficulty in logistics operation. There is a huge gap between domestic and foreign enterprises in the logistics of such products. With the influx of foreign cold chain logistics enterprise for agricultural products, the production frontier shifts towards the foreign countries. The negative impact dwarfs the positive impact of the "technical spillover" of highefficiency foreign-funded enterprises. Of course, domestic enterprises are rapidly catching up in cold chain logistics of agricultural products. For example, some large enterprises from food and pharmaceutical industries have entered the cold chain logistics market of agricultural products. This partially offsets the negative impact of foreign-funded enterprises.

Similar to eastern China, western China suffers from the negative impact of the entry of foreign-funded enterprises. The impact is very obvious due to the relatively weakness of domestic enterprises in this region.

(3) Industrial structure. The development of the tertiary industry in the eastern and western China has greatly improved technical efficiency. In eastern China, the support is prominent because of the high level of the tertiary industry. In western China, however, the support is not obvious as the tertiary industry is relatively backward. In central China, the logistics mainly serves industrial products; the tertiary industry's support to logistics mainly targets the industrial products logistics, while the financial, insurance and information services for agricultural products logistics are far from enough. Hence, the tertiary industry development has a prominent negative impact in central China, contrary to that in the other regions.

(4) Information level. Despite being positive, the $\mathrm{X}_{4}$ variable in each of the three regions was relatively small, revealing the limited promotion effect of information level on technical efficiency. There are three possible reasons for this phenomenon: there is no information release platform specifically designed for agricultural products logistics; the information platforms ran by individuals or enterprises cannot ensure the credibility of the released information; the existing information platforms or channels for agricultural products logistics are isolated from each other.

(5) Institutional environment. In recent years, the stateowned enterprises in China stepped up the efforts to reform and modernize the property rights system. These efforts have solved the absence of a sound liability system, a result of unclear subjects of property rights, and improved the operation efficiency of state-own capital. Finally, the state ownership is no longer synonymous with "inefficiency". The state-owned enterprises in western China lags behind in reform intensity and progress. As a result, the institutional environmental factors in this region have not shown an obvious promotion effect.

\section{CONCLUSIONS}

The main research findings are as follows:

(1) The technical efficiency of agricultural products logistics in China is relatively low and differs from region to region, owing to capital and labor problems in amount, professionality, utilization capability, government control, overflow effect and labor quality.

(2) The traditional mode of agricultural products logistics is centered on multi-level wholesale market. Many new logistics modes, namely, direct purchase and "enterprise + farmer + base", have emerged to solve the defects of the traditional mode. In this case, the scale of agricultural retailing has an unobvious promotion effect of technical efficiency, while that of agricultural processing has an obvious promotion effect of the issue.

(3) The exogenous environment factors exhibit different impacts in different regions. The function mechanism of each impact is closely associated with the economic and social conditions of each region.

\section{ACKNOWLEDGMENT}

This work is supported by Humanities and Social Science Program Found Project among the universities in Jiangxi Province, "Research on technical efficiency level of agricultural products logistics industry in China"(2015,GL1524).

\section{REFERENCES}

[1] Sui, B.W., Zhuang, L. (2015). Selection of third-party logistics provider for agricultural products based on system comprehensive evaluation. Agricultural Science \& Technology, 16(8): 1824-1827.

[2] Accorsi, R., Ferrari, E., Gamberi, M., Manzini, R., Regattieri, A. (2016). A closed-loop traceability system to improve logistics decisions in food supply chains: A case study on dairy products. Advances in Food Traceability Techniques and Technologies, 337-351. http://dx.doi.org/10.1016/B978-0-08-100310-7.00018-1

[3] Lei, M., Luo, S., Deng, Y. (2018). Agricultural product 
logistics efficiency improvement under the dual guidance of supply-side reform and new urbanization-an empirical analysis based on non-parametric DEA and ARDL. Journal of Commercial Economics, (16): 99-102.

[4] Cameron, H.M.G. (2006). Trends in agriculture and agribusiness: knowledge is power. Journal of Business \& Finance Librarianship, 12(1): 3-32. http://dx.doi.org/10.1300/J109v12n01-02

[5] Yang, L., Lu, Q.S. (2018). Research on agricultural product logistics efficiency under government regulation-questionnaire analysis based on changsha modern service integrated pilot project. Logistics Engineering and Management, 40(8): 4-6, 14.

[6] Wang, X.H., Wen, J.Y. (2015). The agricultural products logistics efficiency and its regional difference in China: A SFA method analysis based on provincial panel data. Contemporary Economic Management, 37(1): 26-32.

[7] Farrell, M.J. (1957). The measurement of productive efficiency. Journal of Royal Statistical Society, 120(3): 253-282. http://dx.doi.org/10.2307/2343100

[8] Tone, K. (2001). A Slack-Based Measure of efficiency in data envelopment analysis. European Journal of Operational Research, 130(3): 498-509.

[9] Hall, R.E., Jones, C. (1999). Why do some countries produce so much more output per worker than others? The Quarterly Journal of Economics, 114(1): 83-116.

[10] Zhang, J., Wu, G.Y., Zhang, J.P. (2004). The estimation of China's provincial capital stock: 1952-2000. Economic Research Journal, (10): 35-44.

[11] Huang, Y.F., Ren, R.E., Liu, X.S. (2002). Capital stock estimates in Chinese manufacturing by perpetual inventory approach. China Economic Quarterly, 1(2): 377-396.

[12] Xu, L.P., Li, S.H. (2013). Logistics efficiency of agricultural products and its influencing factors-An empirical analysis based on panel data between 2000 and 2011. Journal of Huazhong Agricultural University (Social Sciences Edition), (6): 71-79.

[13] Yuan, D., Lei, H.Z. (2015). Empirical study on the logistics efficiency of the silk road economic belt and its influencing factors. China Business and Market, (2): 1420.

[14] Ni, M., He, C., Yang, S.L. (2015). Empirical research on logistics efficiency of Jiangxi and its influencing factors. Journal of East China Jiaotong University, 32(4): 65-72.

[15] Tobit, J. (1958). Estimation of relationships for limited dependent variables. Econometrica, 26(1): 24-36. http://dx.doi.org/10.2307/1907382 